\title{
Dialysis vintage stratified comparison of body composition, hydration and nutritional state in peritoneal dialysis and hemodialysis patients
}

\author{
Krzysztof Hoppe ${ }^{1}$, Krzysztof Schwermer ${ }^{1}$, Anna Kawka ${ }^{1}$, Patrycja Klysz², Ewa Baum³ \\ Malgorzata Kaluzna ${ }^{4}$, Dorota Sikorska ${ }^{1}$, Anna Scigacz ${ }^{1}$, Bengt Lindholm ${ }^{5}$, Krzysztof Pawlaczyk ${ }^{1,5}$, \\ Andrzej Oko ${ }^{1}$
}

\author{
${ }^{1}$ Department of Nephrology, Transplantology and Internal Medicine, Poznan University \\ of Medical Sciences, Poznan, Poland \\ ${ }^{2}$ Department of Pathophysiology, Poznan University of Medical Sciences, Poznan, \\ Poland \\ ${ }^{3}$ Department of Philosophy and Bioethics, Poznan University of Medical Sciences, \\ Poznan, Poland \\ ${ }^{4}$ Department of Endocrinology, Metabolic Disorders and Internal Medicine, Poznan \\ University of Medical Sciences, Poznan, Poland \\ ${ }^{5}$ Clinical Science, Intervention and Technology, Karolinska Institutet, Stockholm, \\ Sweden
}

Submitted: 18 February 2016

Accepted: 17 May 2016

Arch Med Sci 2018; 14, 4: 807-817

DOI: https://doi.org/10.5114/aoms.2016.61902

Copyright $\odot 2016$ Termedia \& Banach

\section{Abstract}

Introduction: Body mass decomposition and hydration state imbalances affect patients on maintenance dialysis. We compared body composition, hydration and nutritional state of patients on peritoneal dialysis (PD) and hemodialysis (HD) based on dialysis vintage (DV).

Material and methods: Three hundred and fifty-nine prevalent patients on HD $(n=301)$ and PD $(n=58)$ were divided into 3 subgroups depending on DV: $<2$ years HD $(n=41)$ and PD $(n=28), 2-4$ years $\mathrm{HD}(n=111)$ and PD $(n=17),>4$ years HD $(n=149)$ and PD $(n=13)$. Bioimpedance analysis delivered data including overhydration $(\mathrm{OH})$, Lean (LTM) and adipose lipids mass (FAT). Other measurements included daily diuresis (DD), subjective global assessment (SGA) and serum albumin (alb), C-reactive protein (CRP) and total cholesterol (TChol), and hemoglobin ( $\mathrm{Hb})$.

Results: Dialysis vintage $<2$ years. Hemodialysis patients were older $(65.5$ \pm 18.5 vs. $50.9 \pm 17.1 ; p<0.01)$ with a higher mortality ( 28 vs. $1 ; p<0.01)$ and $\mathrm{OH}(8.0 \pm 4.3$ vs. $1.6 \pm 3.1 ; p<0.001)$. Hemoglobin $(10.6 \pm 1.5$ vs. 11.8 $\pm 1.7 ; p<0.05)$, TChol $(180.2 \pm 47.0$ vs. $211.7 \pm 46.3 ; p<0.05)$, DD $(871 \pm 729$ vs. $1695 \pm 960 ; p<0.001)$ and LTM $(46.5 \pm 12.9$ vs. $53.8 \pm 14.4 ; p<0.05)$ were lower on HD. Dialysis vintage 2-4 years: when compared to PD, HD patients had higher $\mathrm{OH}(11.7 \pm 5.9$ vs. $2.1 \pm 3.2 ; p<0.001)$ and lower $\mathrm{Hb}(10.8 \pm 1.5$ vs. $11.9 \pm 1.4 ; p<0.01)$. Dialysis vintage $>4$ years: compared to PD, HD patients had higher LTM $(44.3 \pm 11.7$ vs. $38.6 \pm 7.9 ; p<0.05)$ and lower FAT $(34.4 \pm 11.1$ vs. $42.8 \pm 6.4 ; p<0.01)$.

Conclusions: Dialysis patients' body composition depends on dialysis modality and DV. Dialysis vintage $<2$ years is associated with better hydration, nutritional state, and survival in PD patients, but longer DV reduces these benefits. Dialysis vintage $>4$ years associated with similar hydration and mortality in both PD and HD while body composition was better on HD.

Key words: hemodialysis, body composition, mortality, peritoneal dialysis, bioimpedance, nutritional state, hydration.

\author{
Corresponding author: \\ Krzysztof Pawlaczyk MD, PhD \\ Department of Nephrology, \\ Transplantology and \\ Internal Medicine \\ Poznan University \\ of Medical Sciences \\ 49 Przybyszewskiego St \\ 60-355 Poznan, Poland \\ Phone: +48 (61) 8691610 \\ Fax: +48 (61) 8691668 \\ E-mail: kpawlac@ump.edu.pl
}




\section{Introduction}

The progression of chronic kidney disease (CKD) to end-stage renal disease (ESRD) is accompanied by the development of a wide variety of complications [1]. Despite renal replacement therapy (RRT), some of these complications appear to be irreversible. The type of RRT itself may be an additional risk factor [2]. A severe complication affecting ESRD patients on maintenance dialysis is body mass decomposition. This pathology is induced by malnutrition, tissue metabolism deregulation with muscle protein breakdown and hydration state imbalances [3-5]. Compared with the general population, malnutrition is a more prominent risk factor for cardiovascular (CV) complications, which are a major cause of death in ESRD patients [6]. The components of malnutrition, inflammation and atherosclerosis (MIA) syndrome have been shown to connect advanced CKD with CV injury [7-10]. The reliable assessment of the ESRD population's nutritional status is problematic due to a lack of objective methods that are both non-invasive and widely available in a clinical setting [11, 12]. Various diagnostic options are currently recommended. The laboratory tests usually include the determination of serum albumin and pre-albumin concentrations, which depend not only on the nutritional state of the patients but also on the presence or absence of an inflammatory state. An inflammatory state would decrease the liver's production of these biomarkers and also increase their external losses [11-14]. Among other indicators, serum cholesterol is affected by medications, serum creatinine is influenced by residual renal function, and normalized protein nitrogen appearance is influenced by the current metabolic state $[11,12]$. Subjective Global Assessment (SGA) is composed of two parts, an interview and physical anthropometric measurements [15]. Its modification, the Malnutrition-Inflammation Score (MIS), includes additional laboratory and body composition indicators [16]. Both methods are also thought to be useful and have been validated for dialysis recipients. Nevertheless, they are substantially dependent on the individual performing the test $[15,16]$. A more novel method is whole-body multiple-frequency bioimpedance analysis (BIA) using the Advanced Model of tissue composition for dialysis patients. Bioimpedance analysis allows for the estimation of lean and adipose tissue body mass $[12,17]$. Bioimpedance analysis also enables researchers to measure body fluid content and its location within the extra- and intracellular compartment. Therefore, BIA appears to be a useful diagnostic method of hydration state estimation $[5,12,18]$. Nevertheless, to address the problem of CKD-derived body decomposition in dialysis patients, an evaluation of modality specific features and the influence of dialysis vintage time is warranted [19-21].

The aim of the study was to compare selected indicators of body composition, as well as hydration and nutritional state, between maintenance peritoneal (PD) and hemodialysis (HD) patients who were stratified according to dialysis vintage (DV). Furthermore, the relationship between these factors, markers of inflammation, and associations with CV-related mortality and all-cause mortality were also analyzed.

\section{Material and methods}

The study investigated a group of 359 Caucasian patients who had received maintenance dialysis treatment during 2010 to 2014. Patients were followed up after 24 months. Three hundred and one patients were undergoing thrice-weekly in-center hemodialysis (group H), and 58 patients had home peritoneal dialysis (group P). Criteria of exclusion featured a history of dialysis modality conversion, RRT vintage shorter than 6 weeks, and age below 18 years. The BIA regimen introduced additional criteria of exclusion, namely pregnancy or lactation, presence of metal implants (e.g. pacemaker, artificial joints) and history of limb amputations. The Poznan University of Medical Sciences Ethical Committee approved the study, and each studied subject provided informed written consent. Data recorded in the patient histories included residual daily diuresis (diuresis), diabetes mellitus (DM), and end-points comprising death, renal transplantation, conversion to another type or disqualification from dialysis. The cause of death was specified as CV (due to ischemic heart disease, stroke, congestive heart failure, sudden cardiac death, peripheral vascular disease) or non-CV. Each main group was divided into three subgroups depending on the DV. Patients in subgroups HA and PA received dialysis for less than 104 weeks (2 years); patients in subgroups HB and PB had dialysis treatment for 104-208 weeks (2-4 years); and patients in subgroups $\mathrm{HC}$ and PC had DV exceeding 208 weeks (4 years).

The following procedures were performed on each studied individual (for HD patients immediately before the midweek dialysis session; for PD patients after the nocturnal peritoneal cavity drainage). The physical examination consisted of mean blood pressure (MBP) determination and whole-body multiple-frequency BIA using a Fresenius Body Composition Monitor. The BIA parameters comprised overhydration to total body weight ratio $(\mathrm{OH})$, body mass index (BMI), lean tissue mass (LTM) and mass of adipose lipids in the body (FAT). Patients were examined in a stable, supine position, using a set of four single-use electrodes placed in pairs on the subject's wrist and ankle on 
the opposite side to the arterio-venous fistula. An SGA questionnaire was performed to assess the nutritional condition and severity of comorbidities. Blood samples were obtained before dialysis for indicators of inflammation, nutrition and prognosis including hemoglobin $(\mathrm{Hb})$, albumin (alb), high sensitivity C-reactive protein (CRP) and total cholesterol (TChol).

\section{Statistical analysis}

Statistical analysis was performed using StatSoft Statistica 12.1.

\section{Results}

\section{Characteristics of investigated HD and PD patients - group H vs. P (details presented in Table I)}

The studied HD population was significantly older, with a higher proportion of men. The mean dialysis vintage was longer for HD patients. Globally, there was no significant difference in the prevalence of DM. The mortality rate was higher for the HD population, with a comparable CV-related mortality percentage in patients on HD and PD. No significant differences were observed for commonly used acute phase proteins, alb and CRP, while mean $\mathrm{Hb}$ was significantly lower in group H. HD patients' mean TChol concentration was significantly lower as well. The SGA questionnaire revealed no differences between $\mathrm{HD}$ and $\mathrm{PD}$ patients. The hydration state reflected by lower diuresis (901 $\pm 777 \mathrm{ml}$ vs. $1500 \pm 922 \mathrm{ml} ; p<0.001$ ) and higher $\mathrm{OH}(10.88 \pm 4.05 \%$ vs. $1.95 \pm 3.10 \%$; $p<0.001)$ was also worse in group $\mathrm{H}$. Nevertheless, no differences in other body mass parameters such as BMI, LTM and FAT were observed. MBP was comparable in the two groups as well. The factors affecting mortality are listed in Table II. Multivariable logistic regression analysis was performed to identify the association of various combinations of analyzed markers with all-cause mortality in patients on HD (Table III). The corresponding models for PD were not possible to build due to the low mortality rate among these patients. The significant covariates of poor prognosis were age $>65$ years, high $\mathrm{OH}$ and FAT, whereas high LTM and HD vintage > 104 weeks were favorable factors.

Dialysis vintage $<2$ years: subgroup HA vs. PA (Table IV)

Among the groups with a short dialysis vintage, patients on HD were significantly older, while the gender distribution was comparable. No significant difference in mean DV or prevalence of DM was noted. A substantial advantage of all- cause and CV mortality was found in group HA. The mean serum concentrations of $\mathrm{Hb}$ and TChol were lower in subgroup HA. Other analyzed markers including CRP, alb, and SGA were also comparable. The HA group exhibited substantially lower diuresis and a higher $\mathrm{OH}$. BIA revealed a higher LTM on PD while FAT and BMI were comparable in HD and PD patients.

\section{Dialysis vintage $2-4$ years: subgroup HB vs. PB (Table V)}

No significant differences in mean age, gender distribution or DV were noted. Comparable incidence of DM and CV and all-cause mortality rate were observed. Differences in the analyzed laboratory nutritional state indicators, alb and TChol, were insignificant. The SGA questionnaire results

Table I. Comparison of groups on hemo- $(\mathrm{H})$ and peritoneal dialysis $(P)$

\begin{tabular}{|c|c|c|c|}
\hline Parameter & $H$ & $P$ & $P$-value \\
\hline Age [years] & $64 \pm 15$ & $56 \pm 17$ & $<0.001$ \\
\hline Patients, $n$ & 301 & 58 & \\
\hline Males/females, $n$ & $190 / 111$ & $28 / 30$ & $<0.05$ \\
\hline $\begin{array}{l}\text { Dialysis vintage } \\
\text { [weeks] }\end{array}$ & $264 \pm 216$ & $135 \pm 96$ & $<0.001$ \\
\hline \multicolumn{4}{|c|}{ Comorbidity and deaths: } \\
\hline $\mathrm{DM}, n$ & 95 & 19 & NS \\
\hline $\begin{array}{l}\text { Deaths } \\
\text { all-cause, } n\end{array}$ & 89 & 6 & $<0.01$ \\
\hline $\begin{array}{l}\text { Deaths } \\
\text { cardiovascular, } n\end{array}$ & 44 & 5 & $<0.001$ \\
\hline \multicolumn{4}{|c|}{ Investigated predictors: } \\
\hline $\mathrm{Hb}[\mathrm{g} / \mathrm{dl}]$ & $10.9 \pm 1.5$ & $11.9 \pm 1.6$ & $<0.001$ \\
\hline Albumin [g/dl] & $3.9 \pm 0.5$ & $3.9 \pm 0.5$ & NS \\
\hline CRP $[\mathrm{mg} / \mathrm{ll}]$ & $16.3 \pm 35.5$ & $9.6 \pm 12.4$ & NS \\
\hline TChol $[\mathrm{mg} / \mathrm{dl}]$ & $177.3 \pm 49.4$ & $198.1 \pm 42.0$ & $<0.001$ \\
\hline SGA [pts] & $9.2 \pm 3.1$ & $8.7 \pm 1.8$ & NS \\
\hline Diuresis [ml] & $901 \pm 777$ & $1500 \pm 922$ & $<0.001$ \\
\hline $\mathrm{MBP}[\mathrm{mm} \mathrm{Hg}]$ & $101.1 \pm 14.7$ & $98.9 \pm 13.1$ & NS \\
\hline $\mathrm{BMI}\left[\mathrm{kg} / \mathrm{m}^{2}\right]$ & $26.4 \pm 4.9$ & $26.2 \pm 5.4$ & NS \\
\hline LTM (\%) & $45.5 \pm 13.2$ & $48.6 \pm 14.0$ & NS \\
\hline FAT (\%) & $35.0 \pm 11.1$ & $35.5 \pm 10.0$ & NS \\
\hline $\mathrm{OH}(\%)$ & $10.9 \pm 4.1$ & $2.0 \pm 3.1$ & $<0.001$ \\
\hline
\end{tabular}

$B M I$ - body mass index, CRP - C-reactive protein, DM - diabetes mellitus, FAT - mass of adipose lipids in the body, $\mathrm{Hb}$ - hemoglobin, LTM - lean tissue mass, MBP - mean blood pressure, $\mathrm{OH}$ - overhydration to total body weight ratio, SGA - Subjective Global Assessment, TChol - total cholesterol. The results are presented as mean \pm standard deviation. 
Table II. Correlations for risk factors of all-cause and CV mortality

\begin{tabular}{|c|c|c|c|c|c|c|c|}
\hline Dialysis/parameter & Parameter & $r$ & $P$-value & Dialysis/parameter & Parameter & $r$ & $P$-value \\
\hline All-cause death: & & & & CV death: & & & \\
\hline HD + PD: & & & & HD + PD: & & & \\
\hline Death & Alb & -0.20 & $<0.05$ & CV Death & Alb & -0.18 & $<0.05$ \\
\hline Death & $\mathrm{Hb}$ & -0.17 & $<0.05$ & CV Death & SGA & 0.15 & $<0.05$ \\
\hline Death & CRP & 0.17 & $<0.05$ & CV Death & LTM & -0.17 & $<0.05$ \\
\hline Death & SGA & 0.18 & $<0.05$ & CV Death & FAT & 0.13 & $<0.05$ \\
\hline Death & LTM & -0.14 & $<0.05$ & CV Death & $\mathrm{OH}$ & 0.13 & $<0.05$ \\
\hline Death & $\mathrm{OH}$ & 0.17 & $<0.05$ & CV Death & Diuresis & -0.19 & $<0.05$ \\
\hline Death & Diuresis & -0.23 & $<0.05$ & HD: & & & \\
\hline HD: & & & & CV Death & Alb & -0.17 & $<0.05$ \\
\hline Death & Alb & -0.20 & $<0.05$ & CV Death & LTM & -0.13 & $<0.05$ \\
\hline Death & $\mathrm{Hb}$ & -0.17 & $<0.05$ & CV Death & FAT & 0.13 & $<0.05$ \\
\hline Death & CRP & 0.18 & $<0.05$ & CV Death & Diuresis & -0.17 & $<0.05$ \\
\hline Death & SGA & 0.18 & $<0.05$ & PD: & & & \\
\hline Death & LTM & -0.13 & $<0.05$ & CV Death & Alb & -0.31 & $<0.05$ \\
\hline Death & $\mathrm{OH}$ & 0.14 & $<0.05$ & Death & SGA & 0.32 & $<0.05$ \\
\hline Death & Diuresis & -0.20 & $<0.05$ & & & & \\
\hline \multicolumn{8}{|l|}{ PD: } \\
\hline Death & Alb & -0.32 & $<0.05$ & & & & \\
\hline
\end{tabular}

CV - cardiovascular, Diuresis - daily residual diuresis, $\mathrm{Hb}$ - hemoglobin, LTM - lean tissue mass, OH - overhydration, SGA - Subjective Global Assessment.

were comparable. Group HB had lower mean levels of $\mathrm{Hb}$ and non-significantly higher CRP (18.54 \pm 44.88 vs. $4.67 \pm 5.71 \mathrm{mg} / \mathrm{l} ; p=0.083$ ). In group $\mathrm{HB}$, the significant advantage in $\mathrm{OH}$ coexisted with higher mean MBP and comparable diuresis. No statistically significant differences in body composition parameters, BMI, FAT and LTM, were observed.

\section{Dialysis vintage $>4$ years: subgroup $\mathrm{HC}$ vs.} PC (Table VI)

The mean age and gender distribution of the two subgroups were comparable. The higher value in the HC group of mean DV almost reached statistical significance (403.72 \pm 232.04 vs. 285.54 \pm 44.47 weeks; $p=0.06$ ). The incidence of DM, $\mathrm{CV}$ and all-cause death rate was comparable. No significant differences were observed for acute phase proteins, alb and CRP. There was a non-significantly lower $\mathrm{Hb}$ level in the $\mathrm{HC}$ group $(1.09 \pm 1.55 \mathrm{~g} / \mathrm{dl}$ vs. $11.98 \pm 1.56 \mathrm{~g} / \mathrm{dl} ; p=0.068)$. The SGA was comparable as well. Group PC had non-significantly higher diuresis $(832 \pm 765 \mathrm{ml}$ vs. $1261 \pm 863 \mathrm{ml} ; p=0.066$ ), with comparable $\mathrm{OH}$. The BIA revealed significant differences between groups $\mathrm{HC}$ and $\mathrm{PC}$ in $\operatorname{LTM}(44.33 \pm 11.74 \%$ vs. $38.63 \pm 7.88 \% ; p<0.05)$ and FAT $(34.39 \pm 11.10 \%$ vs. $42.75 \pm 6.41 \% ; p<0.01)$ and a non-significant difference for BMI $\left(26.20 \pm 4.45 \mathrm{~kg} / \mathrm{m}^{2}\right.$ vs. 28.95 $\left.\pm 5.93 \mathrm{~kg} / \mathrm{m}^{2} ; p=0.066\right)$. The comparative analysis of gender dependent body composition is presented in Figure 1.

\section{Discussion}

The difference in hydration state between the main groups $\mathrm{H}$ and $\mathrm{P}$ is striking. The substantially higher degree of $\mathrm{OH} \%$ in patients on HD may be a reflection of lower mean diuresis among these patients. However, the difference seems to be influenced by other circumstances as well. Patients on PD visited dialysis centers in the morning after the longest nocturnal dialytic fluid exchange, which means that the BIA investigation was performed when hydration could have been at the lowest level. As a full abdomen is suspected to be a factor potentially causing fluid overload overestimation [22], BIA in the present study was performed in PD patients with a drained peritoneal cavity. On the other hand, HD patients underwent the procedure directly before the dialysis session 
Table III. Logistic regression analysis of HD allcause mortality risk factors

\begin{tabular}{|c|c|c|c|}
\hline Variable & OR & $95 \% \mathrm{Cl}$ & $P$-value \\
\hline Model 1: & & & $<0.001$ \\
\hline DM & 0.73 & $0.30-1.81$ & NS \\
\hline DV & 0.21 & $0.09-0.46$ & $<0.001$ \\
\hline Age & 3.25 & $1.29-8.25$ & $<0.05$ \\
\hline $\mathrm{OH}$ & 1.55 & $1.27-1.90$ & $<0.001$ \\
\hline Alb & 0.96 & $0.35-2.64$ & NS \\
\hline FAT & 1.09 & $1.04-1.14$ & $<0.001$ \\
\hline Model 2: & & & $<0.001$ \\
\hline DM & 1.07 & $0.54-2.10$ & NS \\
\hline DV & 0.39 & $0.16-0.92$ & $<0.05$ \\
\hline Age & 0.41 & $0.03-6.20$ & NS \\
\hline $\mathrm{OH}$ & 1.26 & $0.99-1.61$ & 0.055 \\
\hline Alb & 1.20 & $0.54-2.67$ & NS \\
\hline $\mathrm{BMI}$ & 0.94 & $0.84-1.05$ & NS \\
\hline LTM & 0.96 & $0.93-0.99$ & $<0.05$ \\
\hline Model 3: & & & $<0.001$ \\
\hline DV & 0.40 & $0.25-0.63$ & $<0.001$ \\
\hline Age & 2.38 & $1.23-4.61$ & $<0.01$ \\
\hline $\mathrm{OH}$ & 1.31 & $1.14-1.50$ & $<0.001$ \\
\hline Alb & 1.15 & $0.59-2.28$ & NS \\
\hline FAT & 1.04 & $1.01-1.07$ & $<0.05$ \\
\hline
\end{tabular}

Alb - albumin, Cl - confidence interval, DM - diabetes mellitus, DV - dialysis vintage, FAT - mass of adipose lipids in the body, $H D$ - hemodialysis, NS - non-significant $\mathrm{OH}$ - overhydration, $O R$ - odds ratio, SGA - Subjective Global Assessment.

and thus in the state of the highest overhydration. Nevertheless, the mortality risk directly depended on the residual daily diuresis and optimal fluid balance maintenance, which was generally worse on HD. Due to the fact that fluid overload is more stable and continuous on PD, HD recipients are exposed to substantial hydration state fluctuations, leading to an additional $\mathrm{CV}$ burden, a factor which may explain, at least in part, why HD was associated with higher mortality.

The strong overall presence of excessive fluid in $\mathrm{HD}$ recipients was not reflected in lower FAT or LTM. Globally the patients on the two dialysis modalities presented comparable MBP. It seems reasonable to ask about the effects of overhydration prevalence on HD. It is possible that chronic overhydration may be one of the crucial factors responsible for CV system remodeling and injury, and this issue is being addressed in an ongoing study in
Table IV. Comparison of subgroups on hemo- (HA) and peritoneal dialysis (PA) for < 104 weeks (2 years)

\begin{tabular}{|c|c|c|c|}
\hline Parameter & HA & PA & $P$-value \\
\hline Age [years] & $65.5 \pm 18.5$ & $50.9 \pm 17.1$ & $<0.01$ \\
\hline Patients, $n$ & 41 & 28 & \\
\hline Males/females, $n$ & $26 / 15$ & $12 / 16$ & NS \\
\hline $\begin{array}{l}\text { Dialysis vintage } \\
\text { [weeks] }\end{array}$ & $66.4 \pm 26.6$ & $57.0 \pm 26.7$ & NS \\
\hline \multicolumn{4}{|c|}{ Comorbidity and deaths: } \\
\hline $\mathrm{DM}, n$ & 15 & 7 & NS \\
\hline $\begin{array}{l}\text { Deaths } \\
\text { all-cause, } n\end{array}$ & 28 & 1 & $<0.001$ \\
\hline $\begin{array}{l}\text { Deaths } \\
\text { cardiovascular, } n\end{array}$ & 15 & 1 & $<0.01$ \\
\hline \multicolumn{4}{|c|}{ Investigated predictors: } \\
\hline $\mathrm{Hb}[\mathrm{g} / \mathrm{dl}]$ & $10.6 \pm 1.5$ & $11.8 \pm 1.7$ & $<0.05$ \\
\hline Albumin $[\mathrm{g} / \mathrm{dl}]$ & $3.8 \pm 0.5$ & $3.9 \pm 0.5$ & NS \\
\hline $\mathrm{CRP}[\mathrm{mg} / \mathrm{ll}]$ & $31.7 \pm 57.3$ & $10.6 \pm 14.6$ & NS \\
\hline TChol [mg/dl] & $180.2 \pm 47.0$ & $211.7 \pm 46.3$ & $<0.05$ \\
\hline SGA [pts] & $10.5 \pm 3.9$ & $8.6 \pm 2.3$ & NS \\
\hline Diuresis [ml] & $871 \pm 729$ & $1695 \pm 960$ & $<0.001$ \\
\hline $\mathrm{MBP}[\mathrm{mm} \mathrm{Hg}]$ & $95.9 \pm 11.2$ & $101.6 \pm 14.7$ & NS \\
\hline $\mathrm{BMI}\left[\mathrm{kg} / \mathrm{m}^{2}\right]$ & $26.2 \pm 4.7$ & $24.5 \pm 5.00$ & NS \\
\hline LTM (\%) & $46.5 \pm 12.9$ & $53.8 \pm 14.4$ & $<0.05$ \\
\hline FAT (\%) & $35.7 \pm 9.9$ & $31.5 \pm 10.0$ & NS \\
\hline $\mathrm{OH}(\%)$ & $8.0 \pm 4.3$ & $1.6 \pm 3.1$ & $<0.001$ \\
\hline
\end{tabular}

$B M I$ - body mass index, $C R P-C$-reactive protein, $D M-$ diabetes mellitus, FAT - mass of adipose lipids in the body, $\mathrm{Hb}$ hemoglobin, LTM - lean tissue mass, MBP - mean blood pressure, $\mathrm{OH}$ - overhydration to total body weight ratio, SGA - Subjective Global Assessment, TChol - total cholesterol. The results are presented as mean \pm standard deviation.

our center focusing on comparison of CV injury between patients on maintenance $\mathrm{HD}$ and PD.

Being aware of the risk of developing MIA syndrome in ESRD, we introduced a complex of diagnostics featuring laboratory indicators reflecting inflammation and nutrition as well as BIA body composition analysis. SGA with the components of an interview and anthropometric measurements served as a complement of nutritional condition assessment. We observed significant differences only in $\mathrm{Hb}$ and TChol between groups $\mathrm{H}$ and P. Lower mean $\mathrm{Hb}$ levels in the HD population might indirectly suggest malnutrition as well as inflammation or multifactorial anemia. On the other hand, lower mean TChol of group $\mathrm{H}$ to some degree indicates poorer nourishment; however, we cannot exclude it being a result of better lipid control. 
Table V. Comparison of subgroups on hemo- (HB) and peritoneal dialysis (PB) for 104-208 weeks (2-4 years)

\begin{tabular}{|c|c|c|c|}
\hline Parameter & HB & PB & $P$-value \\
\hline Age [years] & $62.7 \pm 16.3$ & $57.8 \pm 17.3$ & NS \\
\hline Patients, $n$ & 111 & 17 & \\
\hline Males/females, $n$ & $66 / 45$ & $8 / 9$ & NS \\
\hline $\begin{array}{l}\text { Dialysis vintage } \\
\text { [weeks] }\end{array}$ & $149.7 \pm 29.2$ & $148.9 \pm 33.2$ & NS \\
\hline \multicolumn{4}{|c|}{ Comorbidity and deaths: } \\
\hline $\mathrm{DM}, n$ & 33 & 7 & NS \\
\hline $\begin{array}{l}\text { Deaths } \\
\text { all-cause, } n\end{array}$ & 23 & 2 & NS \\
\hline $\begin{array}{l}\text { Deaths } \\
\text { cardiovascular, } n\end{array}$ & 12 & 1 & NS \\
\hline \multicolumn{4}{|c|}{ Investigated predictors: } \\
\hline $\mathrm{Hb}[\mathrm{g} / \mathrm{dl}]$ & $10.8 \pm 1.5$ & $11.9 \pm 1.4$ & $<0.01$ \\
\hline Albumin [g/dl] & $3.8 \pm 0.6$ & $3.9 \pm 0.4$ & NS \\
\hline CRP $[\mathrm{mg} / \mathrm{l}]$ & $18.5 \pm 44.9$ & $4.7 \pm 5.7$ & 0.083 \\
\hline TChol $[\mathrm{mg} / \mathrm{dl}]$ & $181.3 \pm 62.2$ & $189.5 \pm 36.0$ & NS \\
\hline SGA [pts] & $9.9 \pm 4.0$ & $8.7 \pm 1.2$ & NS \\
\hline Diuresis [ml] & $1025 \pm 808$ & $1361 \pm 884$ & NS \\
\hline $\mathrm{MBP}[\mathrm{mm} \mathrm{Hg}]$ & $104.7 \pm 15.1$ & $96.9 \pm 11.7$ & $<0.05$ \\
\hline $\mathrm{BMI}\left[\mathrm{kg} / \mathrm{m}^{2}\right]$ & $26.7 \pm 5.5$ & $26.8 \pm 4.9$ & NS \\
\hline LTM (\%) & $46.7 \pm 15.0$ & $48.2 \pm 13.7$ & NS \\
\hline FAT $(\%)$ & $35.6 \pm 11.6$ & $36.0 \pm 9.5$ & NS \\
\hline $\mathrm{OH}(\%)$ & $11.7 \pm 5.9$ & $2.1 \pm 3.2$ & $<0.001$ \\
\hline
\end{tabular}

$B M I$ - body mass index, CRP - C-reactive protein, DM - diabetes mellitus, FAT - mass of adipose lipids in the body, $\mathrm{Hb}$ - he moglobin, LTM - lean tissue mass, MBP - mean blood pressure, $\mathrm{OH}$ - overhydration to total body weight ratio, SGA - Subjective Global Assessment, TChol - total cholesterol. The results are presented as mean \pm standard deviation.

Dialysis vintage-dependent division into subgroups revealed poorer nutritional and hydration states of patients on maintenance HD for less than 104 weeks. Significantly lower diuresis was followed by high excessive fluid accumulation. Comparable BMI and FAT between groups HA and PA coexisting with significantly lower LTM on HD suggest severe body mass decomposition of these patients in comparison with the corresponding PD recipients. The advantage of LTM on PD may to some degree be connected with age-dependent differences, whereas a higher mean TChol level in the younger and more active PD population suggests better nutrition. Moreover, we suspect there is a substantial role played by the circumstances surrounding the initiation of each dialysis modality and the time taken for its preparation.
Table VI. Comparison of subgroups on hemo(HC) and peritoneal dialysis (PC) for > 208 weeks (4 years)

\begin{tabular}{|c|c|c|c|}
\hline Parameter & $\mathrm{HC}$ & $P C$ & $P$-value \\
\hline Age [years] & $64.4 \pm 13.8$ & $63.7 \pm 13.1$ & NS \\
\hline Patients, $n$ & 149 & 13 & \\
\hline Males/females, $n$ & $98 / 51$ & $5 / 8$ & NS \\
\hline $\begin{array}{l}\text { Dialysis vintage } \\
\text { [weeks] }\end{array}$ & $\begin{array}{c}403.7 \\
\pm 232.0\end{array}$ & $\begin{array}{l}285.5 \\
\pm 44.5\end{array}$ & NS \\
\hline \multicolumn{4}{|c|}{ Comorbidity and deaths: } \\
\hline $\mathrm{DM}, n$ & 47 & 5 & NS \\
\hline $\begin{array}{l}\text { Deaths } \\
\text { all-cause, } n\end{array}$ & 38 & 3 & NS \\
\hline $\begin{array}{l}\text { Deaths } \\
\text { cardiovascular, } n\end{array}$ & 17 & 3 & NS \\
\hline \multicolumn{4}{|c|}{ Investigated predictors: } \\
\hline $\mathrm{Hb}[\mathrm{g} / \mathrm{dl}]$ & $12.0 \pm 1.6$ & $12.0 \pm 1.6$ & 0.068 \\
\hline Albumin $[\mathrm{g} / \mathrm{dl}]$ & $4.0 \pm 0.4$ & $3.8 \pm 0.5$ & NS \\
\hline $\mathrm{CRP}[\mathrm{mg} / \mathrm{l}]$ & $13.5 \pm 26.8$ & $16.1 \pm 13.1$ & NS \\
\hline TChol $[\mathrm{mg} / \mathrm{dl}]$ & $175.0 \pm 42.8$ & $181.3 \pm 32.3$ & NS \\
\hline SGA [pts] & $8.9 \pm 2.7$ & $8.8 \pm 1.1$ & NS \\
\hline Diuresis [ml] & $832 \pm 765$ & $1261 \pm 863$ & 0.066 \\
\hline $\mathrm{MBP}[\mathrm{mm} \mathrm{Hg}]$ & $100.2 \pm 14.9$ & $95.6 \pm 10.4$ & NS \\
\hline $\mathrm{BMI}\left[\mathrm{kg} / \mathrm{m}^{2}\right]$ & $26.2 \pm 4.5$ & $29.0 \pm 5.9$ & 0.066 \\
\hline $\operatorname{LTM}(\%)$ & $44.3 \pm 11.7$ & $38.6 \pm 7.9$ & $<0.05$ \\
\hline FAT (\%) & $34.4 \pm 11.1$ & $42.8 \pm 6.4$ & $<0.01$ \\
\hline $\mathrm{OH}(\%)$ & $3.1 \pm 2.8$ & $2.4 \pm 3.3$ & NS \\
\hline
\end{tabular}

$B M I$ - body mass index, CRP - C-reactive protein, DM - diabetes mellitus, FAT - mass of adipose lipids in the body, $\mathrm{Hb}$ - hemoglobin, LTM - lean tissue mass, MBP - mean blood pressure, $\mathrm{OH}$ - overhydration to total body weight ratio, SGA - Subjective Global Assessment, TChol - total cholesterol. The results are presented as mean \pm standard deviation.

The majority of patients who may be unaware of ESRD and who develop clinical symptoms of its decompensation are started on HD. Thus, the short-vintage HD population comprises the majority of subjects with uremia-induced malnutrition and uncontrolled overhydration due to the lack of pre-dialytic nephrological care. More advanced anemia in group HA seems to support the hypothesis of advanced deterioration of ESRD subjects initiating RRT on HD. Therefore HD vintage < 104 weeks was a strong risk factor of death.

Dialysis vintage exceeding 104 weeks diminished the nutritional differences between HD and PD patients. None of the used tools - laboratory markers, BIA or SGA - showed any benefit of one dialysis modality over the other. Nevertheless, the fluid status of HD recipients showed no improve- 
A
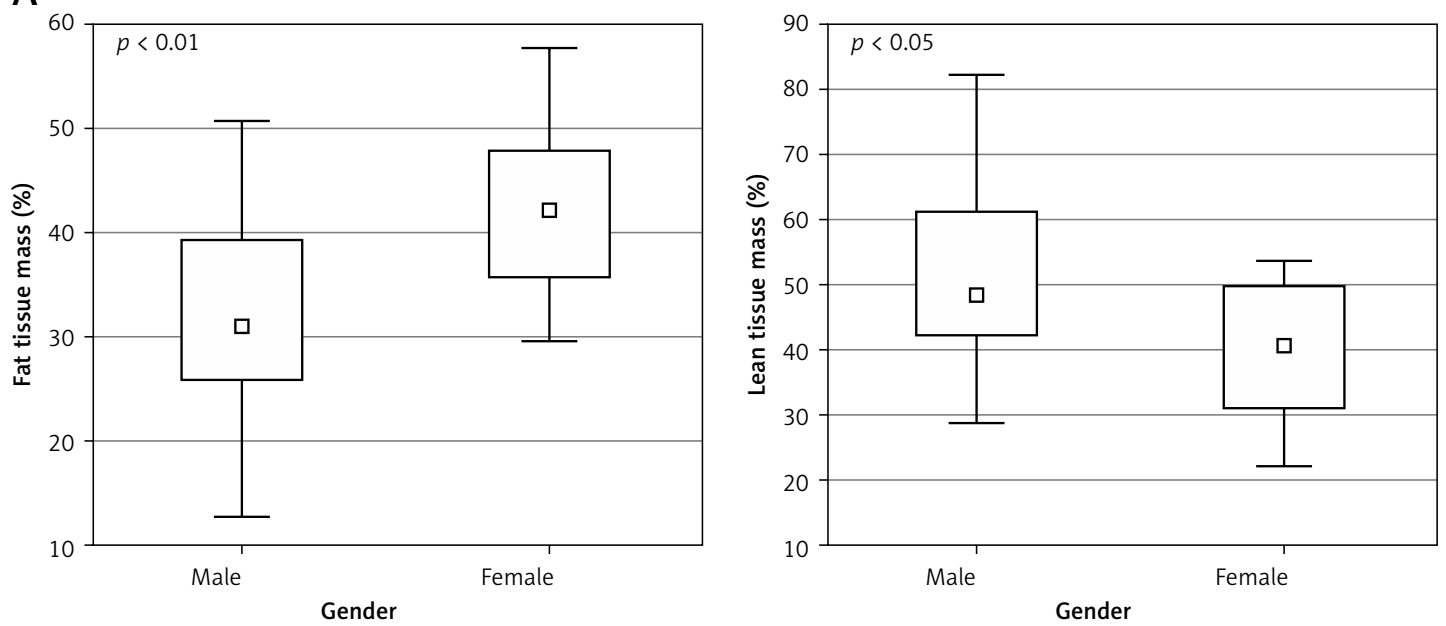

B
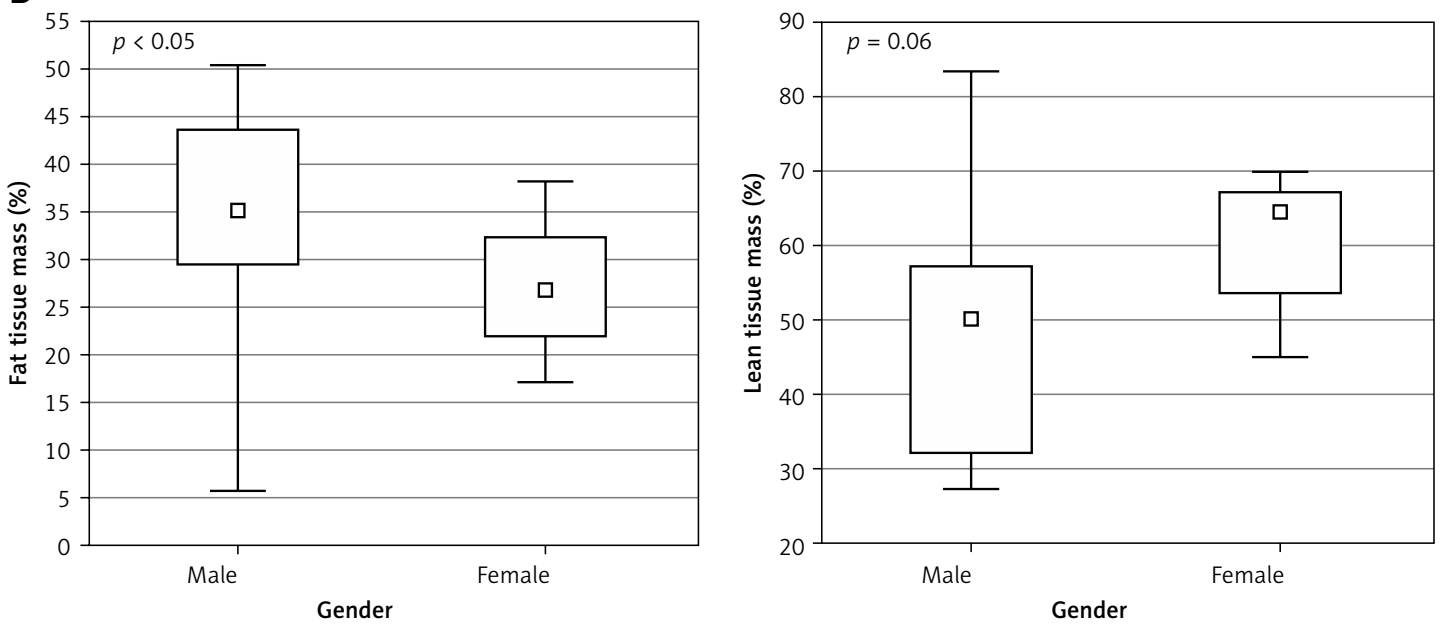

C
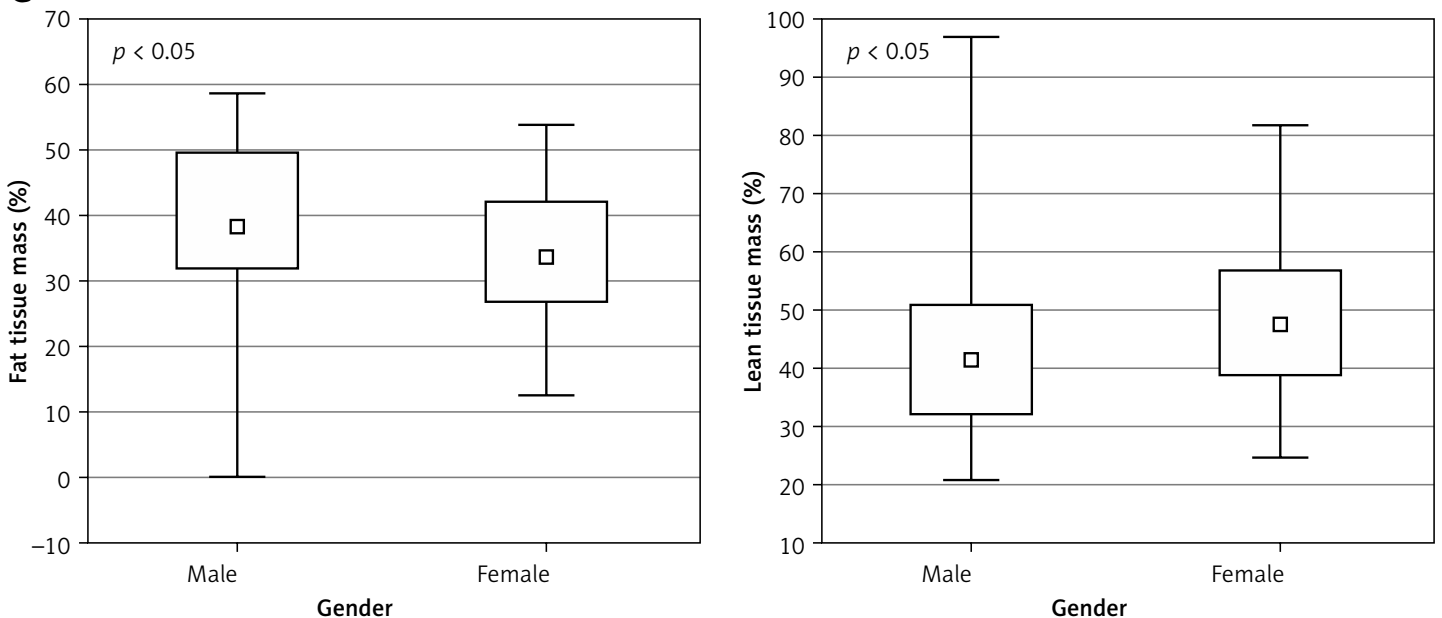

口 Median $\square 25-75 \% \beth$ Min.-max.

Figure 1. Gender dependent body composition of group HA (A), PA (B), HB (C) 
D

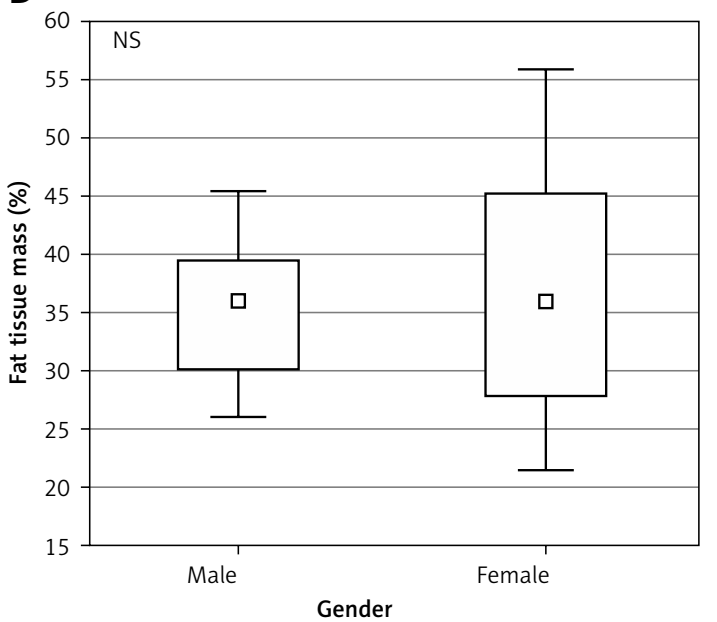

E

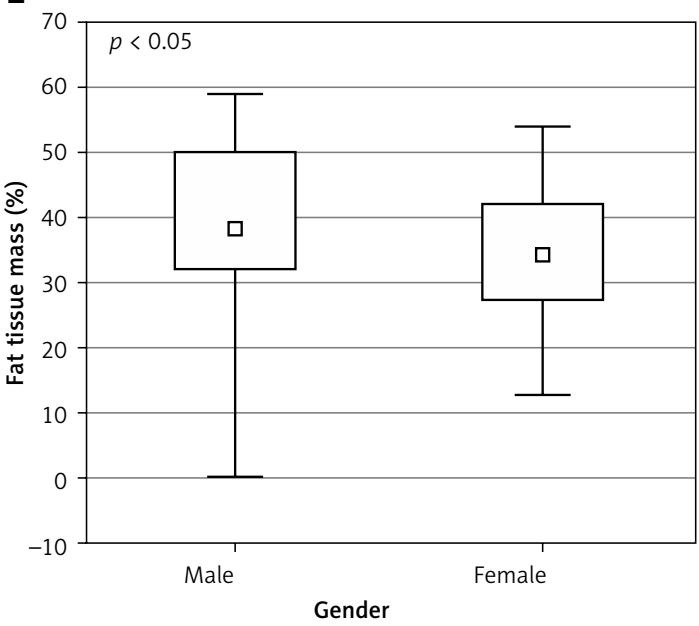

F

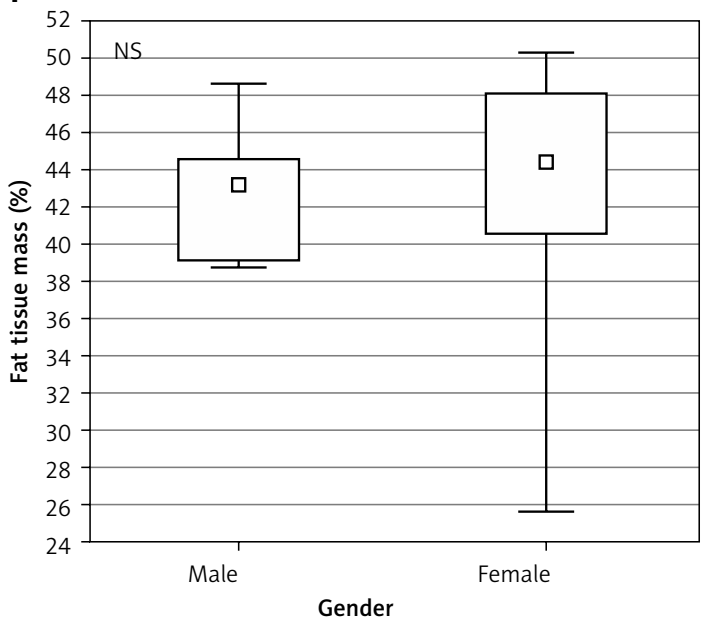

$\square$ median
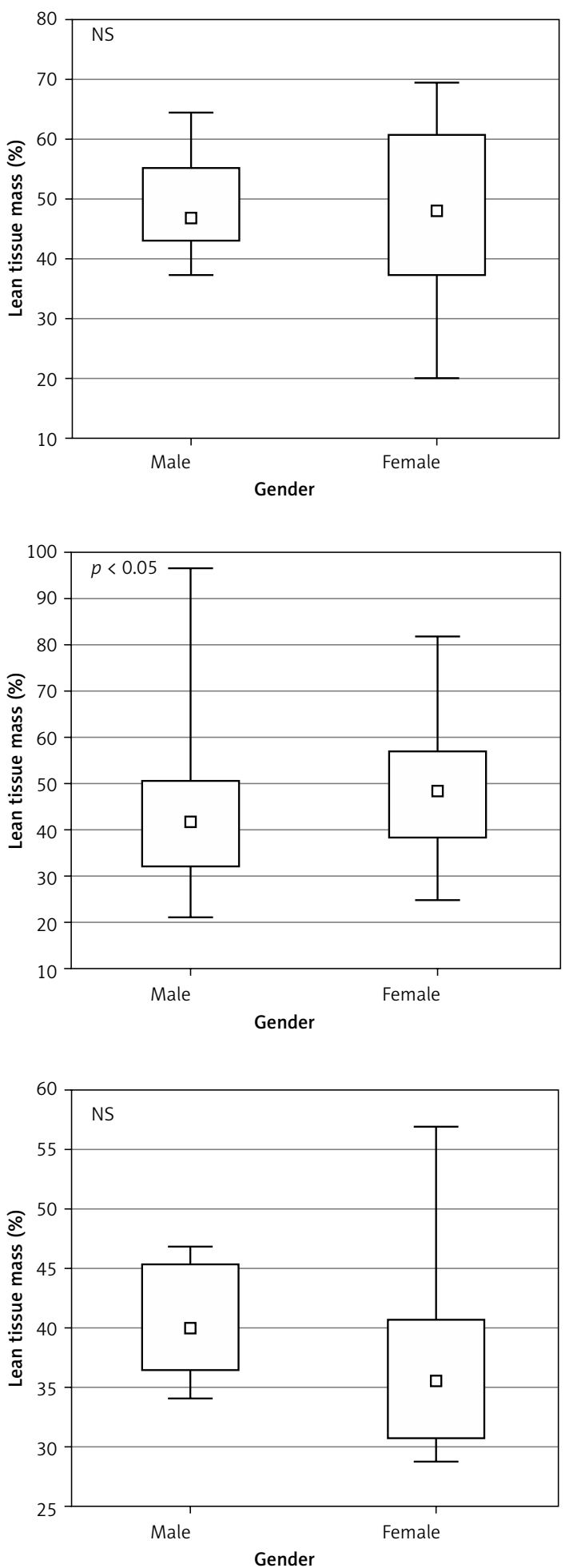

Figure 1 cont. Gender dependent body composition of group PB (D), HC (E), PC (F) 
ment in comparison to subjects on PD with the corresponding vintage. The higher overhydration in group HB was not a result of lower residual daily diuresis. One may speculate that this observation may be explained by better compliance of PD patients in terms of fluid intake regimens. A higher MBP in HB subjects could be induced and attributed to persistent overhydration.

The analysis of long-term dialyzed patients' (HC and PC groups) nutrition and hydration parameters delivered interesting results. The fluid balance measured using BIA was equal for the two dialysis modalities. Subgroup HC showed a tendency for lower residual diuresis, suggesting long-term survival of the patients with optimal compliance and following the fluid intake regimen recommendation. The laboratory markers of nutrition, BMI and SGA revealed no differences between subjects from subgroups $\mathrm{HC}$ and PC; however, there was a disproportion of body composition components. Patients on long-term maintenance HD had a higher percentage of LTM and lower FAT, suggesting more optimal body composition than the corresponding PD recipients.

Up to now, many issues surrounding fluid, nutritional and hydration state comparisons between HD and PD recipients have been analyzed [19-21, 23-27]. However, the present study appears to be the first to explore and compare body composition components of patients on the two dialysis modalities in terms of dialysis vintage using multiple diagnostic methods.

Van Biesen et al. performed a large cohort analysis of BIA-assessed body composition of matched European HD and PD patients [20]. This study comparing pairs of corresponding HD and $P D$ recipients revealed equal $B M I$ and fat tissue index (FTI), which is consistent with our results. On the other hand, the lean tissue index was higher on PD, while we observed no difference. The most unexpected difference between the two studies concerned the hydration state. The group of van Biesen assessed fluid overload with BIA as the overhydration to extracellular water ratio. The analysis for HD was performed before and directly after the midweek session, with a calculation of the time-averaged volume overload (TAVO) of these two results. No difference between PD and pre-HD fluid overload was found, but there was a significantly higher fluid overload in PD as regards TAVO [20]. Nevertheless, no data about studied patients' diuresis were presented. Moreover, in the mentioned cohort analysis, no association between dialysis vintages and a difference between corresponding pairs in FTI and volume overload were noted [20]. Although our analysis lacked the advantage of matching, it revealed significant body composition element differences depending on the dialysis vintage.
Other published studies were performed on non-matched small cohorts and usually without emphasis on dialysis vintage. A Spanish study by Di-Gioia et al. [27] compared BIA body composition parameters between 62 maintenance HD (with 21 subjects using online hemodiafiltration) and 19 PD patients at baseline and after 6 months. Similarly to our study, the PD population had lower dialysis vintage, was younger and presented lower levels of comorbidity. No differences were found in BIA or serum parameters of nutrition, BMI, LTM, FAT and alb. Nevertheless, relative overhydration was significantly higher in HD patients [27]. Thus their results are consistent with our observations.

Mathew et al. recently performed a comparative analysis of fluid balance and nutritional condition of Indian patients [23]. Their study used BIA for body composition assessment and also used several additional nutritional evaluation tools including anthropometric measurements and serum markers (alb, creatinine and $\mathrm{Hb}$ ). In the quantitative $\mathrm{OH}$, all the anthropometric and laboratory parameters were comparable between HD and PD subjects. The results that differed between the groups were that PD patients had higher BMI and FAT, but a lower LTM. The mortality rate was striking. Out of $85 \mathrm{HD}$ patients, only 41 survived, while 6 out of 14 PD recipients expired during the 24-month follow-up period. Their study, performed on a small, non-matched population, did not contain subjects' dialysis vintage [23]. Thus, we are only capable of referring to the overall studied HD and PD populations' comparison. The results of our analysis are inconsistent with the discussed study of Mathew et al. [23]. We observed significantly higher overhydration in the HD group without differences in other body composition parameters.

The study by Yao et al. compared the hydration state of $75 \mathrm{HD}$ and 94 PD recipients in Taiwan using BIA in terms of mortality, blood pressure and cardiac function [24]. The analyzed PD group was, similarly to ours, younger and with less comorbidity. Overhydration was measured before and after each HD session. For PD patients, the BIA was conducted according to our procedure with an empty abdomen. Overhydration on PD was comparable with pre-HD but significantly higher than with post-HD, suggesting overall a higher degree of fluid overload in PD patients. Their results are inconsistent with the considerably higher mean $\mathrm{OH}$ on HD found in our study. Nutritional state markers, dialysis vintage and mortality were not included in their analyses [24]. Other studies based on the use of different BIA tools and methodology also suggested more substantial $\mathrm{OH}$ affecting patients on $\mathrm{PD}[25,26]$.

This prospective observational study carries the limitation of non-matched compared subpop- 
ulations of patients on maintenance HD and PD. This disadvantage leads to a lack of evaluation of the influence of unadjusted demographic factors and comorbidities on measured indicators, which typically affects small group studies. We excluded patients who initiated RRT in a different modality; however, subjects with an unplanned start of HD were qualified. Another limitation is the lower statistical power of our studied group in comparison to large multi-center cohorts.

A major strength of this study is that in this contemporary prospective multifactorial comparison of a Polish cohort of maintenance dialysis patients, patients were stratified both according to dialysis modality and dialysis vintage time. Qualification criteria excluded patients converted from one dialysis modality to another to eliminate this source of bias. We thus could compare subgroups of patients on HD vs. PD for each dialysis vintage period and analyze various nutritional and hydration state parameters, and their influence on mortality. To the best of our knowledge, no previous studies have reported a similar analysis in terms of dialysis vintage.

In conclusion, body composition in ESRD patients on maintenance dialysis is related to markers of nutrition and hydration that depend on dialysis modality and vintage. Globally, patients undergoing HD are affected by higher fluid overload, which is connected with lower residual daily diuresis. However, an objective comparison of estimates of overhydration is almost unobtainable due to the continuous ultrafiltration in PD and in tensive intermittent ultrafiltration in HD. The overall nutritional condition in HD recipients is equal to that in PD patients. Nevertheless, differences in body composition components are revealed if analyzed in dialysis vintage intervals. Patients on maintenance PD for less than 104 weeks present significantly better hydration balance and nutritional state, which is reflected in a lower mortality rate. Longer lasting PD effaces these differences. Patients undergoing dialysis for over 208 weeks have a similar degree of fluid overload in PD and $H D$, whereas the HD recipients' body composition shows a higher percentage of more favorable LTM. Nevertheless, these differences are dependent on the patients' age, general condition and comorbidities. Thus, the precise influence of dialysis modality on body composition is difficult to determine. No reliable single factor of nutritional condition assessment has been proposed. Therefore, we recommend a complex analysis including BIA, SGA and laboratory indicators. The different statistical tools indicated that alb, TChol, SGA, BMI, LTM and FAT can serve as potential mortality predictors. BIA-guided fluid balance determination is proposed as a standard of everyday nephrological care in ESRD subjects due to its reliability, valida- tion, availability and safety. For the maintenance of proper hydration balance we recommend keeping a strict - but not too strict - fluid regimen aiming at preserving residual urine output instead of an indiscriminate increase of dialysis dose or intensiveness.

\section{Conflict of interest}

The authors declare no conflict of interest.

\section{References}

1. National Kidney Foundation. K/DOQI Clinical Practice Guidelines for Chronic Kidney Disease: evaluation, classification and stratification. Am J Kidney Dis 2002; 39 (Suppl 1): S1-266.

2. Kjellstrand CM, Evans RL, Petersen RJ, Shideman JR, von Hartitzsch B, Buselmeier TJ. The "unphysiology" of dialysis: a major cause of dialysis side effects? Hemodial Int 2004; 8: 24-9.

3. Mitch WE. Malnutrition is an unusual cause of decreased muscle mass in chronic kidney disease. J Ren Nutr 2007; 17: 66-9.

4. Anand N, Chandrasekaran SC, Alam NM. The malnutrition inflammation complex syndrome-the micsing factor in the perio-chronic kidney disease interlink. J Clin Diagn Res 2013; 7: 763-7.

5. Wizemann V, Wabel P, Chamney P, et al. The mortality risk of overhydration in haemodialysis patients. Nephrol Dial Transplant 2009; 24: 1574-9.

6. Tsuruya K, Eriguchi M, Yamada S, Hirakata H, Kitazono T. Cardiorenal syndrome in end-stage kidney disease. Blood Purif 2015; 40: 337-43.

7. Pecoits-Filho R, Lindholm B, Stenvinkel P. The malnutrition, inflammation, and atherosclerosis (MIA) syndrome - the heart of the matter. Nephrol Dial Transplant 2002; 17: 28-31.

8. Stenvinkel P, Heimbürger O, Paultre F, et al. Strong association between malnutrition, inflammation, and atherosclerosis in chronic renal failure. Kidney Int 1999; 55 : 1899-911.

9. Chung SH, Stenvinkel P, Heimbürger O, Bergström J, Lindholm B. Prevention and treatment of the malnutrition, inflammation and atherosclerosis (MIA) syndrome in uremic patients. Pol Arch Med Wewn 2000; 104: 645-54.

10. Matuszkiewicz-Rowinska J. The association between malnutrition, inflammation, and atherosclerosis in chronic renal failure. Pol Arch Med Wewn 2002; 108: 901-5.

11. K/DOQI, National Kidney Foundation: Clinical practice guidelines for nutrition in chronic renal failure. Am J Kidney Dis 2000; 35: S1-140.

12. Kuhlmann MK, Levin NW. How common is malnutrition in ESRD? New approaches to diagnosis of malnutrition. Blood Purif 2008; 26: 49-53.

13. Stenvinkel P, Heimbürger O, Lindholm B, Kaysen GA, Bergström J. Are there two types of malnutrition in chronic renal failure? Evidence for relationships between malnutrition, inflammation and atherosclerosis (MIA syndrome). Nephrol Dial Transplant 2000; 15: 953-60.

14. Kaysen GA, Stevenson FT, Depner TA. Determinants of albumin concentration in hemodialysis patients. Am J Kidney Dis 1997; 29: 658-68.

15. Kalantar-Zadeh K, Kleiner M, Dunne E, Lee GH, Luft FC. A modified quantitative subjective global assessment 
of nutrition for dialysis patients. Nephrol Dial Transplant 1999; 14: 1732-8.

16. Brzosko S, Hryszko T, Kłopotowski M, Myśliwiec M. Validation of Mini Nutritional Assessment Scale in peritoneal dialysis patients. Arch Med Sci 2013; 9: 669-76.

17. Tattersall J. Bioimpedance analysis in dialysis: state of the art and what we can expect. Blood Purif 2009; 27: 70-4.

18. Levin NW, Zhu F, Keen M. Interdialytic weight gain and dry weight. Blood Purif 2001; 19: 217-21.

19. Devolder I, Verleysen A, Vijt D, Vanholder R, van Biesen $\mathrm{W}$. Body composition, hydration, and related parameters in hemodialysis versus peritoneal dialysis patients. Perit Dial Int 2010; 30: 208-14.

20. van Biesen W, Claes K, Covic A, et al. A multicentric, international matched pair analysis of body composition in peritoneal dialysis versus haemodialysis patients. Nephrol Dial Transplant 2013; 28: 2620-8.

21. Chertow GM, Johansen KL, Lew N, Lazarus JM, Lowrie EG. Vintage, nutritional status, and survival in hemodialysis patients. Kidney Int 2000; 57: 1176-81.

22. Arroyo D, Panizo N, Abad S, et al. Intraperitoneal fluid overestimates hydration status assessment by bioimpedance spectroscopy. Perit Dial Int 2015; 35: 85-9.

23. Mathew S, Abraham G, Vijayan M, et al. Body composition monitoring and nutrition in maintenance hemodialysis and CAPD patients - a multicenter longitudinal study. Ren Fail 2015; 37: 66-72.

24. Yao YH, Fu CH, Ho SJ, et al. Peritoneal dialysis as compared with hemodialysis is associated with higher overhydration but non-inferior blood pressure control and heart function. Blood Purif 2012; 34: 40-7.

25. Paniagua R, Ventura MD, Avila-Díaz M, et al. NT-proBNP, fluid volume overload and dialysis modality are in dependent predictors of mortality in ESRD patients. Nephrol Dial Transplant 2010; 25: 551-7.

26. Chen YC, Lin CJ, Wu CJ, Chen HH, Yeh JC. Comparison of extracellular volume and blood pressure in hemodialysis and peritoneal dialysis patients. Nephron Clin Pract 2009; 113: 112-6.

27. Di-Gioia MC, Gallar P, Rodríguez I, et al. Changes in body composition parameters in patients on haemodialysis and peritoneal dialysis. Nefrologia 2012; 32: 108-13. 